Research Article

\title{
Cloning, Expression and Purification of Native VP2 Mature Peptide of Canine Parvovirus in Prokaryotic Expression System
}

\author{
Deepika Tuteja', Bhairab Mondal ${ }^{2}$ \\ 1,2Shankaranarayana Life Sciences LLP, Bommasandra industrial area, Bengaluru, Karnataka, India. \\ DOI: https://doi.org/10.24321/2394.6539.201905
}

\section{I $\quad \mathbf{N} \quad \mathbf{F} \quad \mathbf{O}$}

\section{Corresponding Author:}

Bhairab Mondal, Shankaranarayana Life Sciences LLP, Bommasandra industrial area, Bengaluru, Karnataka, India.

E-mail Id:

bhairabmicro21@gmail.com

Orcid Id:

https://orcid.org/0000-0002-3086-0111

How to cite this article:

Tuteja D, Mondal B. Cloning, Expression and Purification of Native VP2 Mature Peptide of Canine Parvovirus in Prokaryotic Expression System. J Adv Res Med Sci Tech 2019; 6(3\&4): 4-7.

Date of Submission: 2020-02-28

Date of Acceptance: 2020-03-25

\section{$\begin{array}{llllllll}\mathbf{A} & \mathbf{B} & \mathbf{S} & \mathbf{T} & \mathbf{R} & \mathbf{A} & \mathbf{C} & \mathbf{T}\end{array}$}

Canine Parvovirus (CPV-2) is a major cause of gastroenteritis in dogs and wild carnivores worldwide. There are three variants of CPV-2 (CPV2a, CPV2b and CPV2c) circulating worldwide and generated due to mutations at VP2 capsid protein. VP2 is the major immuno dominant capsid protein that determines host specificity and diversity of the virus. In the present study, VP2 gene of Canine parvovirus was cloned and purified in E.coli (DE3) expression system. In-silico analysis of transformed $\mathrm{pET} 22 \mathrm{~b}-\mathrm{VP} 2$ sequences were completely matched with amino acids sequences of the selected mature peptide. Purification of the r-VP2 protein was carried out in native condition by Ni-NTA sepharose column chromatography method. The purified protein can be used for development of diagnostics and prophylaxis for Canine Parvovirus (CPV-2).

Keywords: Canine Parvovirus, Cloning, Expression, Purification

\section{Introduction}

Canine parvovirus is an infectious viral pathogen responsible for hemorrhagic diarrhea in dogs and also causes myocarditis in rare cases. ${ }^{1}$ The prevalence of the virus has been documented from various parts of the world: Asia, Africa, America and European countries. ${ }^{2}$ The economical importance of CPV infection is high as it is associated with losses in breeding farms. ${ }^{3}$ The virus can infect any breed irrespective of their age and sex but are mostly fatal in puppies. ${ }^{4}$ The virus is believed to have originated as a variant of Feline Panleukopenia Virus (FPV). There are two subtypes of CPV i.e., CPV-1 and CPV-2. CPV-2 is a major gastrointestinal virus. ${ }^{5}$ It is a single stranded negative sense DNA virus measuring $25 \mathrm{nM}$ in diameter containing icosahedral capsid ( $T=1)$. The genome encodes 2 important structural proteins that forms the capsid of virus - VP1 and
VP2. Around 60 copies of combination of VP1 (727 residues) and VP2 (584 residues) forms the icosahedral capsid. Apart from this, the genome also encodes 2 nonstructural proteins (NS1 and NS2) responsible for virus replication. VP1 contains full length sequence of VP2 along with additional sequence at $\mathrm{N}$ terminal domain. VP2 occupies major part of the capsid and can be proteolytically cleaved by host protease to give rise to VP3. ${ }^{6} \mathrm{VP} 2$ is the major antigenic determinant protein which determines the host specificity of virus. According to the experiments conducted by deturiso and his co-workers the antigen neutralizing epitopes are present at VP2 region. ${ }^{7}$ Continuous mutations in VP2 of the capsid have led to evolution of three variants of CPV-2, i.e., CPV-2a, CPV2b and CPV-2c. ${ }^{8}$ There are several detection systems developed for identification of CPV-2 based on VP2 which includes (PCR), PCR-RFLP (restriction fragment length polymorphism), etc. ${ }^{9}$ 
Several vaccines are available commercially for Canine parvovirus (CPV-2) which includes Vanguard, Nobivac, Intervet; Parvodog, Merial; Quantum, Schering that are specific for particular variant CPV-2a and CPV-2b. However, due to continuous changes at VP2 capsid protein in CPV has reduced the efficiency of these vaccines to protect dog against Canine parvoviral infection. ${ }^{10}$ Therefore, the demand for vaccines based on VP2 has increased. New generation vaccines based on VP2 are under developing stage which includes Viral like particles (VLP) and DNA vaccines etc. ${ }^{11,12}$ Considering these facts, the present study has been undertaken for cloning, expression and purification of VP-2 protein which can be used for development of diagnostic and effective prophylaxis.

\section{Materials and Methodology}

Puppy DP vaccine was purchased from Nobivac. The primers and oligos used in this study were synthesized from Integrated DNA Technologies (IDT, USA). Luria-Bertani (LB) broth and LB agar was purchased from HiMedia (India). Ampicillin and the restriction enzymes (Nco1 and Xho 1) used in this study were purchased from Fisher Scientific (India). All PCR reagents and Calcium Chloride $\left(\mathrm{CaCl}_{2}\right)$ was purchased from Sigma-Aldrich (India). PCR Purification Kit, Plasmid Extraction Kit and Gel Extraction Kit were obtained from Favogen (USA).The chemicals used in the study were molecular grade except mention elsewhere. All the solutions were prepared with ultra-high-purity water (Milli-Q).

\section{Primer Designing}

The gene runner software version 3.05 (http://generunner. net/) was used to design cloning primer for VP-2 gene (Hastings Software Inc., Hastings on Hudson, NY, USA) with reference to GenBank sequences (Table 1). The primers were designed with melting temperature in the range between $54-60^{\circ} \mathrm{C}$, so that annealing temperature should be typically $54-60^{\circ} \mathrm{C}$. The primer was resuspended to a concentration of $100 \mu \mathrm{M}$ in DNA storage buffer $(10 \mathrm{mM}$ Tris- $\mathrm{HCl}, \mathrm{pH} 7.4 \pm 0.2$ ) and stored at $-20^{\circ} \mathrm{C}$. The primers were resuspended in DNA storage buffer to a concentration of $10 \mu \mathrm{M}$ and stored at $-20^{\circ} \mathrm{C}$.

Table I.Oligonucleotide sequences of the primers are used to amplify the VP-2 gene of Canine Parvovirus

\begin{tabular}{|c|c|}
\hline Name & Oligonuclotide Sequences \\
\hline $\begin{array}{c}\text { Nco1 Forward } \\
\text { primer }\end{array}$ & ATGACGGTGGTATGG \\
\hline $\begin{array}{c}\text { Xho } 1 \text { Reverse } \\
\text { primer }\end{array}$ & CCGCTCGAGGCGCTCCCCCCCGTCCTG \\
\hline
\end{tabular}

\section{Plasmid Construction}

Plasmid construction and cloning strategy is deciphered in Figure 1. Viral genomic DNA was extracted from Puppy DP vaccine by using QIAamp MinElute Virus Spin Kit (Qiagen, India) according to the manufacturer's instructions. Full length VP2 was amplified by using cloning primers mentioned in Table 1. PCR was performed in $20 \mu \mathrm{L}$ reaction containing $1.2 \mu \mathrm{L}$ of forward and reverse primer, PCR buffer $2 \mu \mathrm{L}, \mathrm{MgSO}_{4} 1.6 \mu \mathrm{L}, \mathrm{dNTPs} 1 \mu \mathrm{L}$, DNA $1 \mu \mathrm{L}, 0.5 \mu \mathrm{L}$ Pfu DNA polymerase and volume was made up by adding $12.7 \mu \mathrm{L}$ of Mill-Q. The PCR amplification parameter comprise of initial denaturation of $94{ }^{\circ} \mathrm{C}$ for 5 mins followed by 30 cycles of denaturation at $94^{\circ} \mathrm{C}$ for $1 \mathrm{~min}$, annealing at $54{ }^{\circ} \mathrm{C}$ for $1 \mathrm{~min}$, extension at $72{ }^{\circ} \mathrm{C}$ for 2 mins and a final extension for 10 mins at $72{ }^{\circ} \mathrm{C}$. The amplified product was checked by using gel electrophoresis in $1 \%$ agarose gel. The desired band was purified using PCR purification kit and was further subjected to restriction digestion with respective enzymes ( NCO1 and Xho 1). The resultant gene was then ligated into Nco 1 and Xho1 restricted $\mathrm{pET} 22 \mathrm{~b}$ vector. The ligated product was transformed in E.coli BL21 (DE3) cells by $\mathrm{CaCl}_{2}$ mediated transformation. The selection of the transformants was done on Luria agar plates containing $100 \mu \mathrm{g} / \mathrm{mL}$ ampicillin. The recombinant clones were checked further by colony PCR using T7 forward and reverse primer.

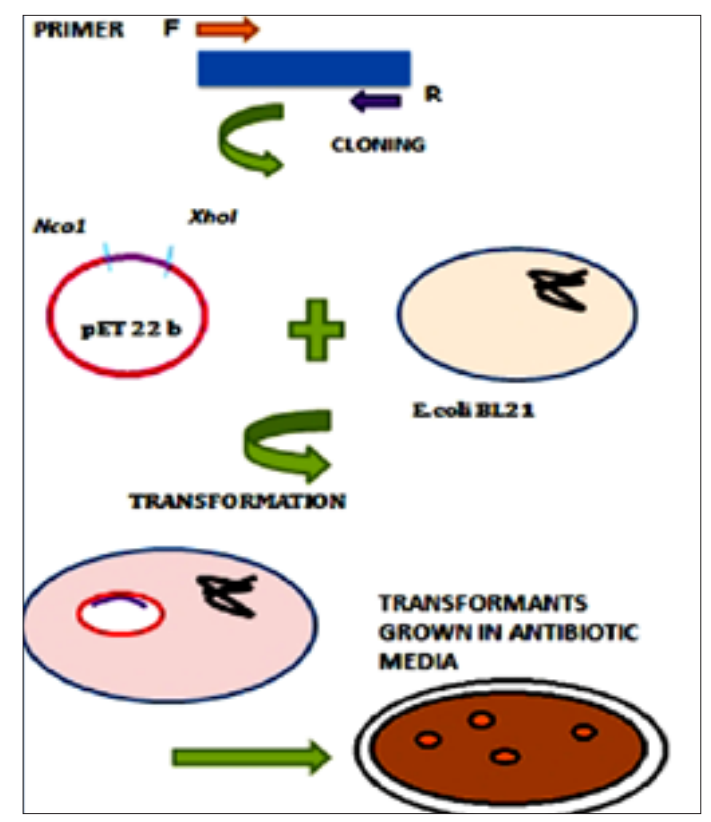

Figure I.Cloning Strategy using pET22b vector Expression and Purification of the r-VP2 Protein

Transformed E.coli BL21 DE3 cells carrying the recombinant plasmid were grown in Luria Bertani broth $(100 \mathrm{~mL})$ containing $100 \mu \mathrm{g} / \mathrm{mL}$ ampicillin at $37^{\circ} \mathrm{C}, 250 \mathrm{rpm}$ in $500 \mathrm{~mL}$ conical flask. The cells were allowed to grow till they reach $0.7 \mathrm{OD}_{600}$. Then cells were induced for $5 \mathrm{hrs}$ with Isopropyl$\beta$-D-1-Thiogalactopyranoside (IPTG) to a final concentration of $1 \mathrm{mM}$ and pelleted. The expression of the induced samples was checked by carrying out SDS-PAGE by taking uninduced sample as control. The localization of expressed recombinant 
proteins in E. coli BL21 DE3 from periplasmic space and cytosol was determined by sequential extraction ${ }^{13}$ and purified under native condition by immobilized Ni-NTA metal affinity chromatography (Qiagen, India) as per manufacturer's protocol. The purification was followed as per Figure 2.

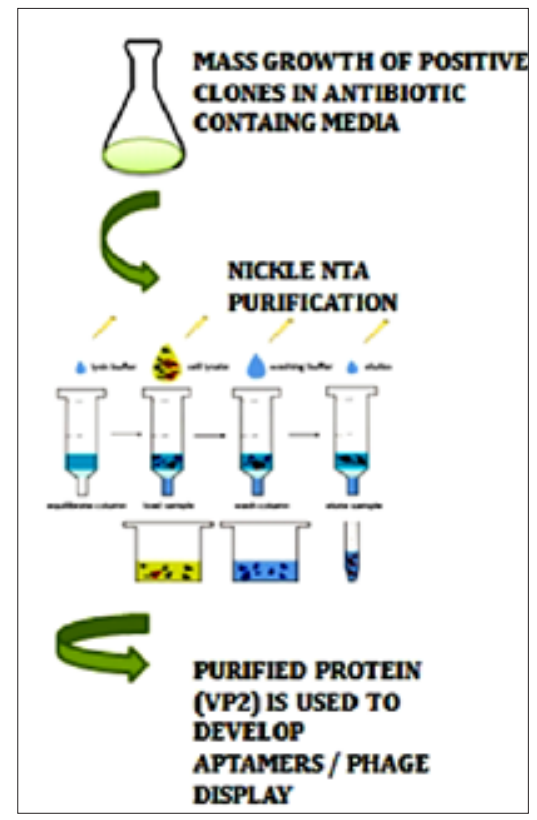

Figure 2.Purification strategy using Ni NTA sepharose

\section{Result}

\section{PCR Amplification of VP2 Gene}

PCR amplification of the target VP2 gene was carried out. Amplification in optimization condition showed a sharp DNA band of expected base size (1069 bp) was observed in agarose gel after 30 cycles of PCR amplification (Figure 3(A)).

\section{Cloning, Expression and Purification of Recombinant VP2 Protein}

The amplified VP2 gene was cloned using pET22b vector and transformed into E. coli BL21DE3 cells. The frame orientation and integrity of recombinant plasmids ( $p E T 22 b$ rVP2) were confirmed by sequence analysis. The r-VP2 chimeric gene was of $1069 \mathrm{bp}$ in length. In-silico translation of transformed cells harbouring recombinant plasmids (pET22b-rVP2) sequences were completely matched with amino acids sequences of the selected mature peptide of VP2 (Gene Bank accession KY399046.1) validates recombinant plasmid integrity. Further, upon induction with 1 mM IPTG, recombinant plasmids harboring $E$. coli (BL21DE3) host cells expressed proteins with apparent molecular weight of 38 $\mathrm{kDa}$. The molecular weight of expressed r-VP2 in 12\% SDSPAGE correlated with the estimated molecular mass (Figure $3(B))$. The soluble recombinant proteins were purified under native conditions employing immobilized metal affinity chromatography using Ni-NTA column (Figure 3(C)).

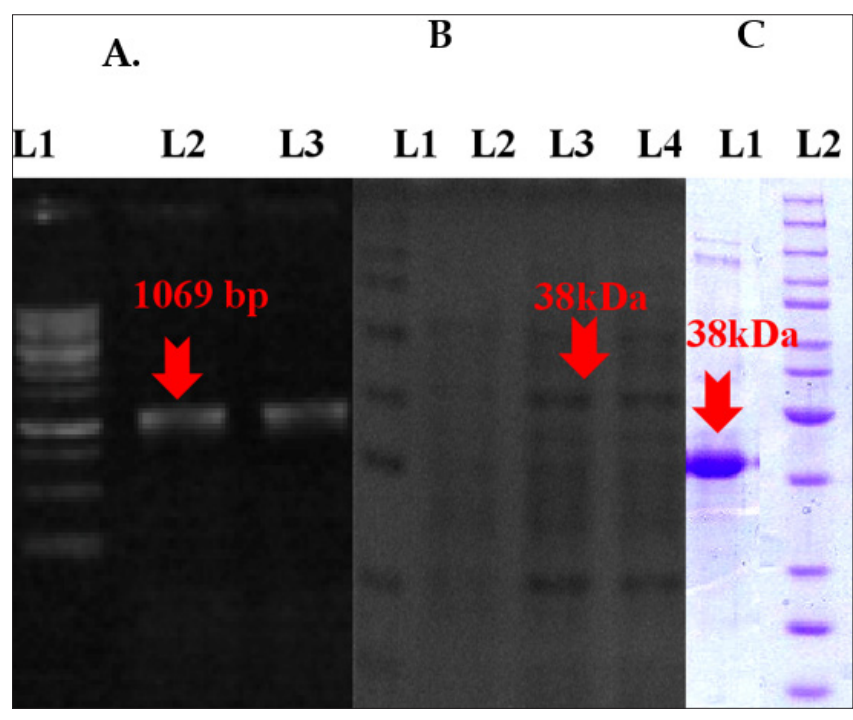

Figure 3.Amplification of VP2 positive clone, Expression, and Purification r-VP2 protein

A: L1: Marker, L2, L3: VP2 positiv e clones B: L1: Marker, L2,: Uninduced Protein L3, L4: Induced Protein C: L1: Purified r-VP2 protein

\section{Discussion}

Canine Parvovirus (CPV) is the one of the major enteric virus accountable for stern enteritis in canids throughout the world. The virus can be frequently detected in both diarrheal and normal feces. ${ }^{1}$ Various detection systems have been developed for CPV-2 at early stage of infection which includes molecular based assays (PCR, RT-PCR and LAMP etc.) and Immunological assays (ELISA, SIT-SAT method, hemagglutination assay etc.). Various prophylaxes are also available for treatment of the disease. ${ }^{9}$ However available detection systems and prophylaxis have their own limitation in various infection scenarios. Hence, new strategy needs to be developed to make effective detection and treatment. VP2 is the major capsid protein of CPV-2 constituting $90 \%$ of the viral capsid that can be cleaved to VP3 by the host proteases. VP2 protein plays an important role in determining antigenicity and host range specificity of CPV-2. Several CPV-2 variants which include CPV-2a, CPV-2b, and CPV-2c, have emerged due to a few amino acid substitutions in VP2 which are responsible for its antigenic properties. ${ }^{14}$ In the present study, cloning expression and purification of mature peptide of VP2 protein was carried out in prokaryotic expression system. For cloning, expression and purification $\mathrm{pET} 22 \mathrm{~b}$ vector was used as the purification of $r$-VP2 can be carried out easily out in native condition by sequential extraction of expressed protein using imidazole buffer. The purified protein was $38 \mathrm{kDa}$ which was exact size of VP2. The purified protein can be used in the development of antibody, aptamer and can be used for development of various innovative diagnostics. Moreover, the protein can be used for development of suitable subunit vaccine candidate. 


\section{Conclusion}

In conclusion, the recombinant VP2 capsid protein gene of CPV-2 was cloned in E. coli BL21DE3. Further the expression was checked and purification was carried out by Ni-NTA chromatography under native condition for development of diagnostics platform and prophylaxis application.

\section{Acknowledgement}

The first author is indebted to Shankaranarayana Life Sciences LLP for providing funding and laboratory facility to carry out the work.

\section{Conflict of Interest: None}

\section{References}

1. Nandi S, Kumar M. Canine parvovirus: current perspective. Indian Journal of virology 2010; 21(1): 31-44.

2. Miranda C, Thompson G. Canine parvovirus: the worldwide occurrence of antigenic variants. Journal of General Virology 2016; 97(9): 2043-2057.

3. Feng $\mathrm{H}, \mathrm{Hu} \mathrm{GQ}$, Wang $\mathrm{HL}$, Liang $\mathrm{M}$, Liang $\mathrm{H}$, Guo $\mathrm{H}$ et al. Canine parvovirus VP2 protein expressed in silkworm pupae self-assembles into virus-like particles with high immunogenicity. PloS one 2014; 9(1).

4. Miranda C, Carvalheira J, Parrish, CR, Thompson, G. Factors affecting the occurrence of canine parvovirus in dogs. Veterinary microbiology 2015; 180(1-2): 59-64.

5. Sun $Y$, Cheng $Y$, Lin $P$, Zhang $H, Y i ~ L$, Tong $M$ et al. Simultaneous detection and differentiation of canine parvovirus and feline parvovirus by high resolution melting analysis. BMC veterinary research 2019; 15(1): 141.

6. Decaro N, Buonavoglia C. Canine parvovirus-a review of epidemiological and diagnostic aspects, with emphasis on type 2c. Veterinary microbiology 2012; 155(1): 1-12.

7. deTuriso JAL, Cortés E, Ranz A, García J, Sanz A, Vela $C$ et al. Fine mapping of canine parvovirus $B$ cell epitopes. Journal of general virology 1991; 72(10): 2445-2456.

8. Ahmed N, Riaz A, Zubair Z, Saqib M, ljaz S, Nawaz-UIRehman et al. Molecular analysis of partial VP-2 gene amplified from rectal swab samples of diarrheic dogs in Pakistan confirms the circulation of canine parvovirus genetic variant $\mathrm{CPV}-2 \mathrm{a}$ and detects sequences of feline panleukopenia virus (FPV). Virology journal 2018; 15(1): 45.

9. Lambe U, Guray M, Bansal N, Kumar P, Joshi VG, Khatri, $R$ et al. Canine Parvovirus-an insight into diagnostic aspect. Journal of Experimental Biology 2016; 4: 3S.

10. Dinçer E. Molecular characterization and phylogenetic analysis of canine parvovirus 2 in dogs, Mersin Province, Turkey. EtlikVeterinerMikrobiyolojiDergisi 2017; 28(2); 96-100.
11. Dahiya SS, Saini M, Kumar P, Gupta PK. Immunogenicity of a DNA-launched replicon-based canine parvovirus DNA vaccine expressing VP2 antigen in dogs. Research in veterinary science 2012; 93(2): 1089-1097.

12. Jin $\mathrm{H}$, Xia X, Liu B, Fu Y, Chen X, Wang $\mathrm{H}$ et al. Highyield production of canine parvovirus virus-like particles in a baculovirus expression system. Archives of virology, 2016; 161(3); 705-710.

13. Singh AK, Kingston JJ, Murali HS, Batra HV, 2014. A recombinant bivalent fusion protein rVE confers active and passive protection against Yersinia enterocolitica infection in mice. Vaccine, 32(11), pp.1233-1239.

14. Nelson, C.D., Minkkinen, E., Bergkvist, M., Hoelzer, K., Fisher, M., Bothner, B. and Parrish, C.R., 2008. Detecting small changes and additional peptides in the canine parvovirus capsid structure. Journal of virology, 82(21), pp.10397-10407. 